\title{
Exposure to solvents and outcome of pregnancy in university laboratory employees
}

\author{
GÖSTA AXELSSON, C LÜTZ, AND R RYLANDER. \\ From the Department of Environmental Hygiene, University of Gothenburg, S-400 33 Gothenburg, Sweden
}

ABSTRACT The outcome of pregnancy was studied among personnel employed in laboratory work at the University of Gothenburg between 1968 and 1979. A questionnaire was distributed to 782 women; the response rate was $95 \%$. When the 1160 pregnancies were divided into those with and without exposure to organic solvents during laboratory work, a slightly increased, but not significant, difference in the miscarriage rate was found (relative risk (RR) $1 \cdot 31,95 \%$ confidence interval 0.89-1.91). No differences in perinatal death rates or the prevalence of malformations were found between infants whose mothers were exposed to solvents and those who were not. Shift work during pregnancy was related to a higher miscarriage rate (RR $3 \cdot 2,95 \%$ confidence interval 1.36-7.47). No relation between cigarette smoking and miscarriage rate was found, although birth weights were lower when the mother smoked during pregnancy.

Several studies have reported a relation between laboratory work, including exposure to organic solvents, and an increased risk of miscarriage. For example, Strandberg et al reported a study of 71 pregnancies in personnel working in hospital laboratories.' Eight of $24(33 \%)$ pregnancies in this group terminated in miscarriage, compared with nine of $47(19 \%)$ in an unexposed group. In another study of 155 pregnancies in laboratory personnel in a large hospital the frequency of miscarriage was $18 \%$ as compared with $7 \%$ in the control group. ${ }^{2}$ Hansson et al examined the miscarriage rate among personnel in pharmaceutical industries and from that of 405 pregnancies, $18 \%$ were miscarriages in those engaged in laboratory work but only $10 \%$ in non-exposed workers. ${ }^{3}$

In these three studies organic solvents were discussed as the possible causative agent for the increase in miscarriage frequency, and exposure to organic solvents has also been associated with an increased frequency of malformations of the central nervous system. ${ }^{4} \mathrm{~A}$ relation between laboratory work and malformations has also been shown in several other studies. ${ }^{35-7}$

Regarding miscarriages among laboratory workers, all investigations mentioned above have used questionnaires and the validity of the information on miscarriage has not been verified by any other

Received 6 January 1983

Accepted 27 April 1983 source, such as hospital registers. The number of pregnancies in the different studies is also rather small, the largest study having comprised only 405 pregnancies.

To study further the relation between laboratory work and pregnancy outcome, and in particular exposure to solvents an investigation was performed among female employees at the University of Gothenburg. Empolyees engaged in laboratory work received a questionnaire concerning any exposure during pregnancy and outcome of pregnancy. Information given in the questionnaires was compared with data in hospital records and central registers. The relation between exposure to solvents and the outcome of pregnancy was then analysed.

\section{Subjects and methods}

Using computerised payrolls, all the women who had worked at the University of Gothenburg could be identified. Women born in 1935 and later and who had been engaged in laboratory work between 1968 and 1979 were selected as subjects for the study. A total of 39 job titles likely to entail laboratory work was identified at the faculties of medicine, odontology, and natural sciences. The most common job titles were laboratory assistant and technician which together made up about $90 \%$ of the total.

The names and social security numbers of 811 women in these job categories were obtained from the payrolls and their current addresses were 305 
identified using the State Person and Address Register. Of these, 782 women could be identified; the remainder had either emigrated or died.

The subjects received a questionnaire on outcome of pregnancy and exposure during pregnancy. A reminder was mailed three weeks later to those who had not answered and a second reminder was sent two weeks later. Those who were pregnant at the time the questionnaire was distributed received a new questionnaire after delivery.

In the questionnaire, information was sought on all pregnancies, including induced abortions and ectopics. Further questions about occupation during pregnancy (gainful employment, education pursuit, housework) and the exposure to solvents during laboratory work, both during the first trimester and the remainder of the pregnancy. Smoking habits, consumption of medicines, and diseases during pregnancy were also investigated. Regarding outcome of pregnancy questions were posed on duration of gestation, delivery date, sex, and birth weight of the child, perinatal mortality, and malformations. For miscarriages, questions were posed on when they occurred and whether the miscarriage had been verified by a physician.

Information on the 782 women in the study was also sought in the Medical Birth Register in Sweden that was started in 1973. The registration is based on a medical birth registration form that is part of a standardised record system for maternal health care, obstetric care, and child health care. A copy of the medical birth registration form is sent to the National Board of Health and Welfare for all newborn babies, living and stillborn. The register contains such administrative data as place of residence, hospital, social security number, marital status, and medical data of both mother and child. For cases in which the number of pregnancies in the questionnaire did not correspond with the data in the Medical Birth Register hospital records were investigated.

Information on malformations was also obtained from the Swedish Register of Congenital Malformations. This register was established in 1965 and comprises mainly serious malformations detected during the neonatal period. If no information was available in the register data were sought in hospital records.

Miscarriages reported in the questionnaire were included in the study only if they could be verified in hospital records or, if medical attendance had not been obtained, if they were anamnestically reported. An experienced gynaecologist examined all doubtful hospital records.

Information on the number of pregnancies among the non-respondents was obtained from the Medical
Birth Register and by screening hospital records in the three largest hospitals in the Gothenburg area.

The miscarriage rate was defined as the number of miscarriages divided by the number of miscarriages + the number of induced abortions + the number of births, according to Hemminki et al. ${ }^{8}$

An analysis of possible risk factors for miscarriage, such as infectious disease, taking of medicines, work with $x$ ray and radioactive isotopes, heavy lifting, stress, and shift work, was made. The age adjusted relative risk for these factors was calculated using the Mantel-Haenszel procedure. ${ }^{9}$ The $95 \%$ confidence interval of the relative risk (RR) was calculated according to the method described by Miettinen. ${ }^{10}$ Possible confounding factors to exposure to solvents, such as pregnancy number, age, year of pregnancy, previous miscarriage, and shift work, were evaluated using a multiple regression technique. Spearman correlation coefficients were calculated using standard statistical programs at the Gothenburg University computing centre."

When testing for the relation between work with solvents during the first trimester and the miscarriage frequency, the material was stratified with regard to pregnancy number $(1,2, \geqslant 3)$ and age $(-19,20-24,25-29,30-34, \geqslant 35$ years). The pregnancies during shift work were not included in this analysis.

The children with malformations were divided into two groups according to whether or not the mothers were exposed to solvents during the first trimester.

Birth weight was analysed using a multiple regression technique, taking into consideration laboratory work during pregnancy, exposure to solvents, duration of pregnancy, pregnancy number, parity, smoking habits, sex of infant, and birth type (singleton or twins, for example).

\section{Results}

\section{PARTICIPATION AND REPORTED NUMBER OF} PREGNANCIES

In all, 745 of the 782 subjects answered the questionnaire $(95 \%)$. Of those, 556 reported that they had been pregnant. Information on the outcome of pregnancy was obtained for 31 of the 37 women who had not answered the questionnaire.

Table 1 shows the number of pregnancies among the responders and non-responders. Among those who answered the questionnaire, several unreported pregnancies, particularly miscarriages and induced abortions, were found when Medical Birth Register data were analysed. The miscarriage rate among those who did not answer the questionnaire was larger than among the respondents $(15.7 \%$ versus 
Table 1 Outcome of pregnancy in female personnel responding and not responding to questionnaire

\begin{tabular}{|c|c|c|c|c|c|}
\hline & Delivery & Induced abortion & Miscarriage & Total & Miscarriage rate (\%) \\
\hline $\begin{array}{l}\text { Responders: } \\
\text { Data in questionnaire } \\
\text { Data not reported in questionnaire } \\
\text { Non-respondents } \\
\text { Total }\end{array}$ & $\begin{array}{r}997 \\
1 \\
49 \\
1027\end{array}$ & $\begin{array}{l}64 \\
14 \\
10 \\
88\end{array}$ & $\begin{array}{r}119 \\
9 \\
11 \\
139\end{array}$ & $\begin{array}{r}1160 \\
24 \\
70 \\
1254\end{array}$ & $\begin{array}{l}10.3 \\
37.5 \\
15.7 \\
11.1\end{array}$ \\
\hline
\end{tabular}

Table 2 Outcome of pregnancy related to main occupation during pregnancy

\begin{tabular}{|c|c|c|c|c|c|}
\hline & Delivery & Induced abortion & Miscarriage & Total & Miscarriage rate $(\%)$ \\
\hline $\begin{array}{l}\text { Laboratory work } \\
\text { Laboratory study } \\
\text { Other employment } \\
\text { Other studies } \\
\text { Disease } \\
\text { Work at home }\end{array}$ & $\begin{array}{r}677 \\
13 \\
116 \\
39 \\
7 \\
125\end{array}$ & $\begin{array}{r}33 \\
11 \\
9 \\
7 \\
0 \\
4\end{array}$ & $\begin{array}{r}78 \\
2 \\
21 \\
7 \\
1 \\
10\end{array}$ & $\begin{array}{r}788 \\
26 \\
146 \\
53 \\
8 \\
139\end{array}$ & $\begin{array}{r}9 \cdot 9 \\
7 \cdot 7 \\
14 \cdot 4 \\
13 \cdot 2 \\
12 \cdot 5 \\
7 \cdot 2\end{array}$ \\
\hline
\end{tabular}

$10 \cdot 8 \%$, but the difference was not statistically significant.

Nineteen miscarriages reported in the questionnaires were excluded from the material. Seventeen of these could not be found in hospital records as events or as reported anamnestically. For the two remaining cases, hospital records could not be obtained.

\section{MISCARRIAGES AND PERINATAL DEATHS}

Table 2 shows the outcome of the pregnancies reported in the questionnaires with relation to the primary occupation during pregnancy. The miscarriage rate was not higher in pregnancies in progress when laboratory work was performed than in preganancies occurring under other conditions of work. The number of induced abortions was unevenly distributed among the different groups and was more common in those who had pursued educational goals during the pregnancy.

Table 3 reports the outcome of pregnancy with relation to smoking habits before and during pregnancy. No increased miscarriage rate could be detected among smokers. The table also shows that several women decreased their cigarette consumption during pregnancy.

Table 4 shows the age adjusted relative risk of miscarriage (risk ratio with $95 \%$ confidence limit) for infectious diseases, consumption of medication, and working conditions during the first trimester. A significantly increased miscarriage risk $(R R=3 \cdot 19)$ was found for whose who reported shift work during the pregnancy but no significantly increased risk for miscarriage could be found for the other factors. The pregnancy number, age, and shift work were significantly negatively correlated with working with solvents $(p<0.0001, p=0.038$, and $p<0.0001$, repectively). All these factors thus contribute to an increase in the miscarriage rate in the group of pregnancies not exposed to solvents.

Table 5 shows the outcome of pregnancy related to solvent exposure during the first trimester. The highest miscarriage rate $(11.5 \%)$ was found among those women who were not engaged in laboratory work or in laboratory studies during the first trimester. The slightly increased miscarriage rate in the exposed group $(10.6 \%)$ compared with the three others combined $(10 \cdot 1 \%)$ was not statistically

Table 3 Outcome of pregnancy related to smoking habits shortly before and during pregnancy

\begin{tabular}{|c|c|c|c|c|c|}
\hline Smoking habits & Delivery & Induced abortion & Miscarriage & Total & Miscarriage rate (\%) \\
\hline $\begin{array}{l}\text { No of cigarettes a da } \\
0 \\
1-5 \\
6-10 \\
>10 \\
\text { No information }\end{array}$ & $\begin{array}{c}\text { gnancy: } \\
588 \\
88 \\
149 \\
148 \\
4\end{array}$ & $\begin{array}{r}35 \\
3 \\
6 \\
12 \\
8\end{array}$ & $\begin{array}{r}77 \\
13 \\
16 \\
12 \\
1\end{array}$ & $\begin{array}{r}700 \\
104 \\
171 \\
172 \\
13\end{array}$ & $\begin{array}{r}11.0 \\
12.5 \\
9.4 \\
7.0 \\
7.7\end{array}$ \\
\hline $\begin{array}{l}\text { No of cigarettes a da } \\
0 \\
1-5 \\
6-10 \\
>10 \\
\text { No information }\end{array}$ & $\begin{array}{c}\text { gnancy: } \\
695 \\
95 \\
91 \\
93 \\
3\end{array}$ & $\begin{array}{r}39 \\
2 \\
4 \\
11 \\
8\end{array}$ & $\begin{array}{r}86 \\
13 \\
11 \\
8 \\
1\end{array}$ & $\begin{array}{r}820 \\
110 \\
106 \\
112 \\
12\end{array}$ & $\begin{array}{r}10.5 \\
11.8 \\
10.4 \\
7.1 \\
8.3\end{array}$ \\
\hline
\end{tabular}


Table 4 Age adjusted risk ratio of miscarriage related to infectious disease, medication, and work conditions during first trimester

\begin{tabular}{lll}
\hline & Risk ratio & $\begin{array}{l}95 \% \text { Confidence } \\
\text { interval }\end{array}$ \\
\hline $\begin{array}{l}\text { Infectious disease* } \\
\begin{array}{l}\text { Medication* category } \\
\text { B3, C, D }\end{array}\end{array}$ & 1.04 & $0.76-1.42$ \\
$\begin{array}{l}\text { Work with x ray or } \\
\quad \text { radioactive isotopes }\end{array}$ & 0.56 & $0.18-1.70$ \\
$\begin{array}{l}\text { Heavy lifting } \\
\text { Stress }\end{array}$ & 1.36 & $0.38-1.53$ \\
Shift work & 0.90 & $0.91-2.02$ \\
\hline
\end{tabular}

*Question not specific to the first trimester.

†Category B3 = indications of reproductive effects from toxicological studies; $C$ = suspected to be harmful for the fetus because of its pharmacological effects; and $\mathrm{D}=$ teratogens.

significant $\left(\chi^{2}=1 \cdot 95, \mathrm{RR}=1 \cdot 31,0.89-1.91\right)$ after adjustment for the three confounders. The proportion of miscarriages occurring after the sixteenth week of pregnancy was $0.7 \%$ in the exposed group and $1.0 \%$ in the three others combined. The corresponding figures for perinatal deaths were $1.2 \%$ and $1.0 \%$, respectively.

Table 6 shows the relationship between the frequency of exposure to solvents ("sometime per month" to "daily") and miscarriage rate. No differences were found between the different groups, nor were any trends to a dose response relationship seen.

Table 7 shows the miscarriage rate with relation to different types of solvents used. The first seven solvents in the table were specified in the questionnaire, whereas the remaining solvents were indicated by the respondents. Those who reported exposure to petroleum ether had a slightly increased miscarriage rate (observed 6, expected 2.04 $\mathrm{p}=0 \cdot 02)$.

\section{MALFORMATIONS}

Table 8 gives the number of malformations verified in the registers or hospital records. Eighteen malformations were found among the 492 children for which a maternal exposure to solvents was reported (3.7\%) and 21 among the 496 unexposed (4.2\%). Serious malformations in the exposed group were one Down's syndrome, one anal atresia, one anencephalia, and two hypospadias. In the nonexposed group the serious malformations were one pes equinovarus, one bile duct atresia, one oesophageal atresia with tracheo-oesophageal fistula, and three serious heart malformations one of which also had hypospadia.

\section{BIRTH WEIGHTS}

The average birth weight reported in the questionnaire for pregnancies during which an exposure to solvents took place during the second and third trimester was $3456 \pm 522 \mathrm{~g}$. For unexposed pregnancies the birth weight was $3467 \pm 544 \mathrm{~g}$.

Table 9 shows the relation between birth weights, laboratory work, exposure to solvents, and different factors known to influence birth weight. Smoking, the duration of the pregnancy, pregnancy number, and sex of the infant were all significantly correlated with birth weight. For the period 1973-81, birth weights were also obtained from the Medical Birth Register. The average weight for exposed pregnancies was $3473 \pm 509 \mathrm{~g}$, and $3509 \pm 555 \mathrm{~g}$ for unexposed.

Table 5 Outcome of pregnancy related to solvent exposure at work during first trimester

\begin{tabular}{|c|c|c|c|c|c|}
\hline & Delivery & Induced abortion & Miscarriage & Total & Miscarriage fate (\%) \\
\hline $\begin{array}{l}\text { No laboratory work/studies } \\
\text { Laboratory work/studies: }\end{array}$ & 272 & 20 & 38 & 330 & $11 \cdot 5$ \\
\hline $\begin{array}{l}\text { No work with solvents } \\
\text { Others in same room working }\end{array}$ & 134 & 7 & 14 & 155 & $9 \cdot 0$ \\
\hline $\begin{array}{l}\text { with solvents } \\
\text { Work with solvents } \\
\text { No information }\end{array}$ & $\begin{array}{r}82 \\
489 \\
0\end{array}$ & $\begin{array}{r}3 \\
26 \\
8\end{array}$ & $\begin{array}{r}6 \\
61 \\
0\end{array}$ & $\begin{array}{r}91 \\
576 \\
8\end{array}$ & $\begin{array}{r}6 \cdot 6 \\
10 \cdot 6 \\
-\end{array}$ \\
\hline
\end{tabular}

Table 6 Outcome of pregnancy related to frequency of work with solvents during first trimester

\begin{tabular}{|c|c|c|c|c|c|}
\hline & Delivery & Induced abortion & Miscarriage & Total & Miscarriage rate (\%) \\
\hline $\begin{array}{l}\text { Some time per month } \\
\text { Some time per week } \\
\text { Several times a week } \\
\text { Daily } \\
\text { No information }\end{array}$ & $\begin{array}{r}43 \\
140 \\
188 \\
114 \\
4\end{array}$ & $\begin{array}{r}1 \\
6 \\
9 \\
10 \\
0\end{array}$ & $\begin{array}{r}6 \\
16 \\
23 \\
16 \\
0\end{array}$ & $\begin{array}{r}50 \\
162 \\
220 \\
140 \\
4\end{array}$ & $\begin{array}{r}12 \cdot 0 \\
9.9 \\
10 \cdot 5 \\
11 \cdot 4 \\
\end{array}$ \\
\hline
\end{tabular}


Table 7 Outcome of pregnancy related to type of solvent used during first trimester

\begin{tabular}{|c|c|c|c|c|c|}
\hline & Delivery & Induced abortion & Miscarriage & Total & Miscarriage rate (\%) \\
\hline $\begin{array}{l}\text { Chloroform } \\
\text { Methylene chloride } \\
\text { Toluene } \\
\text { Acetone } \\
\text { Xylene } \\
\text { Ether } \\
\text { Benzene } \\
\text { Methanol } \\
\text { Ethanol } \\
\text { Propylenoxide } \\
\text { Dichlorethane } \\
\text { Phenol } \\
\text { Formaldehyde } \\
\text { Petroleum ether } \\
\text { Other solvents }\end{array}$ & $\begin{array}{r}128 \\
28 \\
140 \\
145 \\
160 \\
226 \\
35 \\
23 \\
14 \\
18 \\
13 \\
5 \\
5 \\
15 \\
88\end{array}$ & $\begin{array}{r}6 \\
1 \\
9 \\
9 \\
14 \\
9 \\
1 \\
0 \\
1 \\
2 \\
0 \\
0 \\
2 \\
0 \\
2\end{array}$ & $\begin{array}{r}14 \\
4 \\
17 \\
22 \\
20 \\
21 \\
5 \\
5 \\
3 \\
4 \\
2 \\
0 \\
3 \\
6 \\
12\end{array}$ & $\begin{array}{r}148 \\
33 \\
166 \\
176 \\
194 \\
256 \\
41 \\
28 \\
18 \\
24 \\
15 \\
5 \\
10 \\
21 \\
102\end{array}$ & $\begin{array}{r}9 \cdot 5 \\
12 \cdot 1 \\
10 \cdot 2 \\
12 \cdot 5 \\
10 \cdot 3 \\
8 \cdot 2 \\
12 \cdot 2 \\
17 \cdot 9 \\
16 \cdot 7 \\
16 \cdot 7 \\
13 \cdot 3 \\
\overline{30} \cdot 0 \\
28 \cdot 6 \\
11 \cdot 8\end{array}$ \\
\hline
\end{tabular}

\section{Discussion}

This investigation studied women who, at some time between 1968 and 1979, had worked in a laboratory. The miscarriage rate for pregnancies during laboratory work was compared with the miscarriage rate when no laboratory work took place. This approach offers certain advantages over a study where an unexposed control group is selected for comparison.

Working in an occupational area in which a sus-

Table 8 Malformations related to work with solvents during first trimester

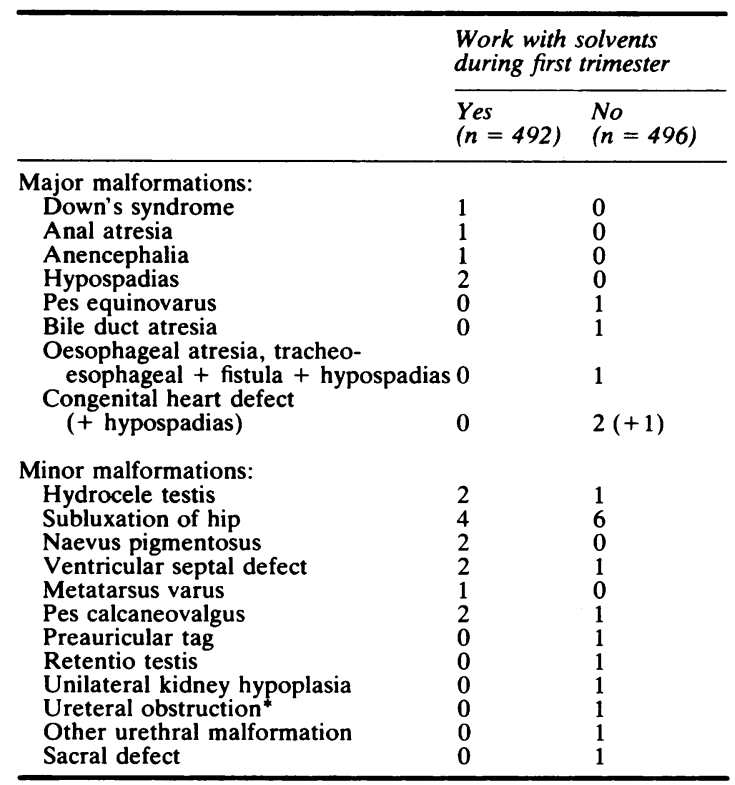

${ }^{*}$ Diagnosis at 5 years of age. pected hazardous exposure is present could increase the motivation to answer the questionnaire. Choosing only one occupational group diminishes the risk of difference in socioeconomic conditions between exposed and non-exposed women. Such factors are potential confounders in occupational studies of miscarriages. ${ }^{8}$

A disadvantage with the approach used in this study is that a mutagenic effect occurring during laboratory work could theoretically cause a miscarriage even after the woman has stopped working at the laboratory. ${ }^{12}$ Thus the exposure could influence the miscarriage rate in the control group. If an increased miscarriage rate had been seen among those who were exposed during the first trimester, this should be interpreted as a teratogenic effect of exposure.

Studies of miscarriage rates in different occupational groups could be biased due to selection. Women who have had a successful pregnancy more often terminate their employment than women who have had a miscarriage. ${ }^{27}$ In the present study this bias is insignificant as women who had terminated their employment were included.

Postal questionnaires or interviews are the most common sources of information in studies of the relation between occupational exposure and miscarriage. The methodological shortcomings of these techniques have been discussed earlier..$^{13-15}$ Uncertainty about the diagnosis, a low response rate, and selection of the response group are major sources of error. It was shown in a study on personnel exposed to anaesthetic gases that the non-respondents in a mail questionnaire study $(21 \%)$ were selected both regarding exposure and outcome of pregnancy. ${ }^{16}$ In the present study the response rate was high $(95 \%)$. It is thus not likely that the slightly higher miscarriage frequency in the non-respondent group could have significantly influenced the results. Regarding 
Table 9 Relation between birth weight, solvent exposure, and known risk indicators for low birth weight. For each variable the correlation coefficient, number of infants, and a $p$ value of the correlation is given

\begin{tabular}{|c|c|c|c|c|c|c|c|}
\hline & $\begin{array}{l}\text { Birth } \\
\text { weight }\end{array}$ & $\begin{array}{l}\text { Work with } \\
\text { solvents }\end{array}$ & $\begin{array}{l}\text { Work in } \\
\text { laboratory }\end{array}$ & $\begin{array}{l}\text { Cigarette } \\
\text { consumption }\end{array}$ & $\begin{array}{l}\text { Gestational } \\
\text { duration }\end{array}$ & Parity & $\begin{array}{l}\text { Sex of } \\
\text { infant }\end{array}$ \\
\hline $\begin{array}{l}\text { Birth } \\
\text { weight }\end{array}$ & 1 & $\begin{array}{r}0.028 \\
.968 \\
0.379\end{array}$ & $\begin{array}{r}-0.015 \\
962 \\
0.647\end{array}$ & $\begin{array}{c}-0.111 \\
965 \\
0.0005\end{array}$ & $\begin{array}{c}0.308 \\
964 \\
0.0001\end{array}$ & $\begin{array}{c}0.116 \\
968 \\
0.0003\end{array}$ & $\begin{array}{c}-0.159 \\
967 \\
0.0001\end{array}$ \\
\hline $\begin{array}{l}\text { Work with } \\
\text { solvents }\end{array}$ & & 1 & $\begin{array}{c}0.937 \\
982 \\
0.0001\end{array}$ & $\begin{array}{r}0.088 \\
985 \\
0.006\end{array}$ & $\begin{array}{r}0.018 \\
984 \\
0.567\end{array}$ & $\begin{array}{c}-0.117 \\
988 \\
0.0002\end{array}$ & $\begin{array}{r}-0.038 \\
987 \\
0.228\end{array}$ \\
\hline $\begin{array}{l}\text { Work in } \\
\text { laboratory }\end{array}$ & & & 1 & $\begin{array}{c}0.073 \\
979 \\
0.022\end{array}$ & $\begin{array}{r}0.032 \\
978 \\
0.310\end{array}$ & $\begin{array}{c}-0.147 \\
982 \\
0.0001\end{array}$ & $\begin{array}{r}-0.027 \\
981 \\
0.403\end{array}$ \\
\hline $\begin{array}{l}\text { Cigarette } \\
\text { consumption }\end{array}$ & & & & 1 & $\begin{array}{r}0.032 \\
981 \\
0.324\end{array}$ & $\begin{array}{r}-0.055 \\
985 \\
0.086\end{array}$ & $\begin{array}{r}-0.034 \\
984 \\
0.293\end{array}$ \\
\hline $\begin{array}{l}\text { Gestational } \\
\text { duration }\end{array}$ & & & & . & 1 & $\begin{array}{c}0.004 \\
984 \\
0 \cdot 910\end{array}$ & $\begin{array}{r}-0.003 \\
983 \\
0.931\end{array}$ \\
\hline Parity & & & & & & 1 & $\begin{array}{r}0.034 \\
987 \\
0.280\end{array}$ \\
\hline Sex of infant & & & & & & & 1 \\
\hline
\end{tabular}

the accuracy of the diagnosis, reports of miscarriages that could not be validated in hospital records were excluded from the material.

Retrospective investigations on large materials have reported miscarriage frequencies of between 12 and $15 \% . .^{17-19}$ Prospective studies have shown frequencies in this range ${ }^{2021}$ as well as lower figures. ${ }^{22}$ Even if comparisons of studies are difficult due to different definitions of miscarriage and different types of study design, the proportion of miscarriages in the present study $(11.9 \%$ excluding legal abortions) can be considered normal.

Induced abortions are excluded in most investigations on miscarriage. If a high frequency of induced abortions is present the number of successful pregnancies is reduced and the miscarriage frequency thus increases. An uneven distribution of induced abortions between exposed and unexposed women could influence the validity of the calculated miscarriage rates. Previous studies have shown that differences in the miscarriage ratio can be present between different occupational groups but that these differences are reduced when the number of induced abortions is taken into consideration. ${ }^{8}$

The number of induced abortions in this study was small-only 9.0 per 100 live births during the period 1976-80. The corresponding figure for Sweden during 1977 was $33 \cdot 5 .^{23}$ This difference is considerable even if a certain underreporting of induced abortions is probably present in questionnaire investigations. ${ }^{16}$ The low frequency of induced abortions indicates that the population studied is selected with regard to social/educational factors.

No relation between smoking and a high miscarrige rate could be seen. As smoking was strongly associated with a reduced birth weight, the reported cigarette consumption was considered to be valid. Smoking has been associated with an increased miscarriage risk in several studies, reviewed by Abel. ${ }^{24}$ A low proportion of smokers, a socially homogenous group, and a different study design are some possible explanations for the lack of correlation in this study.

The only factor in the environment that could be related to an increase in the frequency of miscarriage was shift work. This observation warrants further study to evaluate the importance of factors such as stress, changes in diurnal rhythm, and population selection mechanisms for pregnancies in shift workers.

Regarding laboratory work, three previous investigations have shown an increased miscarriage rate..$^{1-3}$ The relation in the present study between exposure to organic solvents during the first trimester and miscarriage rate was weaker and not statistically significant. No dose-response relationship regarding frequency of exposure and miscarriage rate could be seen.

Many women reported that it was difficult to remember the types of solvents used during pregnancy. None of the seven solvents specified in the questionnaire was associated with a high miscarriage rate. Among the other agents, exposure to petroleum ether and formaldehyde during pregnancy 
showed the highest miscarriage rate. As the number of pregnancies in these groups is small, it is not possible to draw conclusions about causal relations. In a Finnish study on hospital staff exposed to sterilising agents no correlation between exposure to formaldehyde and an increased miscarriage rate could be found. ${ }^{25}$

For the miscarriages reported in the questionnaire that could not be verified in hospital records, exposure to solvents was reported more frequently than for miscarriages that were medically verified or anamnestically mentioned. If all miscarriages reported in the questionnaires had been accepted together with their exposure information the difference in the miscarriage rate between unexposed and exposed would have attained statistical significance (12.7\% versus $10.8 \%$, RR $1.43,95 \%$ confidence limits $1 \cdot 02-2 \cdot 00$ ).

The previously reported suspected relation between exposure to organic solvents and malformations could not be supported in this study. The number of serious malformations was small, both in the exposed group and control group and the number of minor malformations was not overrepresented in the exposed group.

Selevan had calculated that 600 infants in the exposed and unexposed groups are needed to detect a fivefold increase of a malformation with a prevalence at birth in the reference population of $0.6 \% .^{26}$ Because of the size of this study, an increased risk for a single type of serious malformations could not be excluded.

The results from this investigation cannot be used to disregard laboratory work during pregnancy as a risk factor for pregnancy interference. Laboratory work is a general term that implies exposure to a variety of agents. Previous studies could thus have involved exposure to agents not present in the University of Gothenburg laboratories. The reported exposure conditions for the unverified miscarriages in this study suggest, however, that methodological shortcomings could be a factor contributing to the differences in miscarriage rate observed in previous studies.

Unless the information obtained in questionnaire on outcome of pregnancy has been verified using other sources of information, reported differences in miscarriage frequency between exposed and nonexposed groups should be treated with caution.

This work was supported by a grant from the Swedish Work Environment Fund (81/0192). We thank Dr Margareta Unander for her examination of hospital records and Björn Areskoug for computing help.

\section{References}

' Standberg M, Sandbäck K, Axelson O, Sundell L. Spontaneous abortions among women in hospital laboratory. Lancet 1978;i:384-5.

${ }^{2}$ Kolmodin-Hedman B, Hedström L. Questionnaire concerning spontaneous abortions among chemical exposed laboratory workers. Läkartidningen 1978;75:3044-5.

${ }^{3}$ Hansson E, Jansa S, Wande H, Källén B, Östlund E. Pregnancy outcome for women working in laboratories in some of the pharmaceutical industries in Sweden. Scand $J$ Work Environ Health 1980;6:131-4.

${ }^{4}$ Holmberg P. Central-nervous-system defects in children born to mothers exposed to organic solvents during pregnancy. Lancet 1979;ii: 177-8.

${ }^{5}$ Meirik O, Källén B, Gauffin U, Ericson A. Major malformations in infants born of women who worked in laboratories while pregnant. Lancet 1979;ii: 91.

- Blomqvist U, Ericson A, Källén B, Westerholm P. Delivery outcome for women working in the pulp and paper industry. Scand J Work Environ Health 1981;7:114-8.

${ }^{7}$ Ericson A, Källén B, Meirik O, Westerholm P. Gastointestinal atresia and maternal occupation during pregnancy. JOM 1982;24:515-8.

${ }^{8}$ Hemminki K, Niemi M-L, Saloniemi I, Vainio H, Hemminki E. Spontaneous abortions by occupation and social class in Finland. Int J Epidemiol 1980;9:149-53.

9 Mantel N, Haenszel W. Statistical aspects of the analysis of data from retrospective studies of disease. JNCI 1959;22:719-48.

${ }^{10}$ Miettinen OS. Simple interval estimation of risk ratio. Am J Epidemiol 1974;100:515-6.

" SAS Institute. SAS user's guide (statistical analysis system). North Carolina: SAS Institute, 1979.

${ }^{12}$ Hemminki K, Sorsa M, Vainio H. Genetic risks caused by occupational chemicals. Scand J Work Environ Health 1979;5:307-27.

${ }^{13}$ Leridon $\mathrm{H}$. Facts and artifacts in the study of intra-uterine mortality: a reconsideration from pregnancy histories. Population studies 1976;30:319-35.

14 Jansen R. Spontaneous abortion incidence in the treatment of infertility. Am J Obstet Gynecol 1982;143:451-73.

${ }^{15}$ Hemminki K, Axelson O, Niemi M-L, Ahlborg G. Assessment of methods and results of reproductive occupational epidemiology: spontaneous abortions and malformations in the offspring of working women. Am J Ind Med 1983;4:293-307.

${ }^{16}$ Axelsson G, Rylander R. Exposure to anaesthetic gases and spontaneous abortions: response bias in a postal questionnaire study. Int J Epidemiol 1982;11:250-6.

17 Warburton D, Fraser FC. Spontaneous abortion risks in man: data from reproductive histories collected in a medical genetics unit. Am J Hum Genet 1964;16:1-25.

${ }^{18}$ Naylor AF. Sequential aspects of spontaneous abortion: maternal age, parity and pregnancy compensation artifact. Soc Biol 1974;21:195-204.

"Shapiro S, Levine H, Abramowicz M. Factors associated with early and late fetal loss. Excerpta Medica International Congress Series 1970;224:45-63.

${ }^{20}$ Pettersson F. Epidemiology of early pregnancy wastage. Stockholm: Scandinavian University Press, 1968.

${ }^{21}$ Miller JF, Williamson E, Glue J, Gordon YB, Grudzinskas J, Sykes A. Fetal loss after implantation. A prospective study. Lancet 1980; ii:554-6.

${ }^{22}$ Royal College of General Practitioners' oral contraception study. The outcome of pregnancy in former oral contraceptive users. Br J Obstet Gynaecol 1976;83:608-16.

${ }^{23}$ Official Statistics of Sweden. Abortions 1978. Statistical reports HS 1980:8. Stockholm: National Central Bureau of Statistics, 1980.

${ }^{24}$ Abel E. Smoking during pregnancy: a review of effects on growth and development of offspring. Hum Biol 1980;52:593-625. 
${ }^{25}$ Hemminki K, Mutanen P, Saloniemi I, Niemi M-L, Vainio H. Spontaneous abortions in hospital staff engaged in sterilising instruments with chemical agents. Br Med J 1982;285:1461-3.

${ }^{26}$ Selevan S. Design of pregnancy outcome studies of industrial exposures. In: Hemminki K, Sorsa M, Vainio H, eds. Occupa- tional hazards and reproduction. Hemisphere Publishing Co. (in press).

${ }^{27}$ Axelsson G. Selection bias in occupational studies of spontaneous abortion. JOM (in press). 